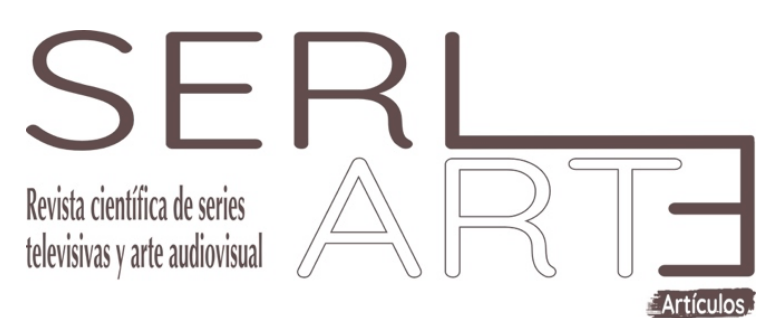

\title{
Fantasmas del lejano Oriente. Mitología y plasmaciones en la SERIE FOLKLORE DE HBO
}

\section{GHOST OF THE FAR EAST. MYtHOLOGY AND IMPRESSIONS IN HBO'S FOLKLORE SERIES}

\author{
Antonio Míguez Santa Cruz \\ Universidad Católica Junshin de Nagasaki \\ gesto tecnico@hotmail.com \\ ORCiD https://orcid.org/0000-0001-7610-5616
}

\section{Resumen}

Como en su momento sucedió con el cine de monstruos clásicos de la Universal y la Hammer, o el subgénero slasher a partir de 70's, el llamado J-Horror (Japanese Horror) provocó un oleaje de explotación que inundó las carteleras de todo el mundo. El mérito hemos de atribuírselo a Sadako, aquella mujer que irrumpiera espasmódica a través de la televisión, y cuya fuerza visual acabó por condicionar la forma en que se imaginó al fantasma en el s. XXI.

Mas el yūrei o espectro japonés no es la única criatura sobrenatural arraigada en el imaginario asiático, un hecho constatable si echamos una ojeada a las distintas plataformas de streaming, donde multitud de películas tailandesas, singapurenses, malayas, o indias, exponen su mitología secular por medio de filmes protagonizados por entes sobrenaturales de lo más diverso. Tal vez el ejemplo más notable lo encontremos en Folklore, una serie de mediometrajes de terror auto conclusivos que cuentan con la particularidad de descubrir el tipo de espíritu más representativo de cada país asiático. Nuestro objetivo en este 
artículo será realizar un análisis antropológico de cada criatura, al tiempo que analizamos cinematográficamente los distintos episodios.

\section{Abstract}

As in its time happened with the classic monster movies of Universal and Hammer, or the slasher subgenre from the 70's onwards, the so-called J-Horror (Japanese Horror) caused a wave of exploitation that flooded billboards around the world. We must give credit to Sadako, that specter that burst spasmodically through television, and whose visual force ended up conditioning the way in which the specter was imagined in the 21 st century.

But the yūrei or Japanese ghost is not the only supernatural creature rooted in the Asian imaginary, a fact that can be verified if we look at the different streaming platforms, where a multitude of Thai, Singaporean, Malaysian or Indian films expose their secular mythology through films starring the most diverse supernatural entities. Perhaps the most notable example is Folklore, a series of self-concluding medium-length horror films that have the particularity of presenting the most representative type of specter of each Asian country. Our objective in this article will be to make an anthropological analysis of each creature, while cinematographically analyzing the different episodes.

\section{Palabras clave}

Fantasma; Asia; Explotación; Mitología; Comparativa; Terror; Series

\section{Keywords}

Ghost; Asia; Explotation; Mythology; Comparison; Horror; Series

\section{Abriendo el círculo}

El terror está de moda. Antaño condenado al menoscabo mayoritario de crítica y público, y sobreviviendo al cálido pero ingrato amparo de la subcultura geek, en la actualidad se revigoriza como nunca había sucedido. Tal aseveración podría resultar contraproducente, pues incluso entre las mismas comunidades de nostálgicos se extiende la idea de que todas las producciones posteriores a 80's suponen una degeneración del género. Ahora bien, la experiencia vivida en la última década apunta más bien a todo lo contrario, sobre todo 
considerando algunos films insuperables como La Bruja (The Witch, Robert Eggerts, 2015), Hereditary (Ari Aster, 2018), La llorona (Jayro Bustamante, 2019) o The Vigil (Keith Thomas, 2019), cuyos altísimos logros técnicos y narrativos han llevado a acuñar el concepto de "Elevated horror" para denominar esta clase de estilización cinematográfica.

Tampoco debemos pensar que las anteriores perlas impliquen un mayor talento promedio en los directores, sino más bien una proporción consecuente respecto al aumento per se de producciones de terror, que no hace sino expandirse como género narrativo, ya sea en forma de creepypasta por youtube, survival horrors dentro del mundo del videojuego, o series surgidas al calor del streaming y su intuitiva manera de entender el entretenimiento. Y he aquí donde queríamos llegar: las historias de miedo han conquistado un formato hasta hace no tanto vedado para ellas (la TV), algo constatable simplemente echando un vistazo a la casi nula presencia de títulos memorables antes de 2012, fecha clave para la internacionalización del fenómeno Netflix (Hidalgo, 2020: 117).

Precisamente una de aquellas pocas series de terror notables-como decíamos, anteriores a las plataformas en red- fue Masters of Horror (2005), un compendio de mediometrajes coordinados por Mick Garris, donde intervinieron gran parte de los directores más renombrados del género, pese a que algunos llevasen Iustros sin rodar ese tipo de cine (Casas, 2014: 68). El resultado fue en parte irregular, pero se creó un formato fresco y ágil en el que la experimentación y los hallazgos de episodios superiores (Imprint, Takeshi Miike), se mezclaron con el evidente anquilosamiento de parte de aquel roster de cineastas.

Después de varios intentos frustrados por seguir explotando el mismo formato de antología (Terror en estado puro, Masters of Sci-Fi), HBO -la otra cadena por cable americana par excellence, hoy día competidora en la carrera del streaming doméstico- decidiría darle una vuelta de tuerca a la concepción de serie de terror situándola en un contexto geográfico muy concreto: Asia. Como es ampliamente conocido, el cine de fantasmas asiático se popularizó a principios de siglo gracias al éxito sin paliativos de Ringu (Hideo Nakata, 1998), generando un oleaje de títulos de explotación que inundó las salas de cine y videoclubs de todo el Globo (Olivares, 2005: 34). Aunque el gusto del público 
generalista hacia el neo-kaidan' se diluyera prematuramente a la altura de 2006, su impronta quedó grabada por siempre en el género hasta replantear visualmente el aspecto de los fantasmas, por no hablar del selecto fandom que aún hoy reverencia el J-Horror con una pasión difícilmente objetivable, pero tan real y sincera como el pavor que los asiáticos sienten por estas criaturas tan arraigadas en su cultura (Malpartida, 2015: 21).

El encargado de coordinar esta nueva serie de terror exclusivamente asiático sería el singapurense Eric Khoo, único dinamizador de la industria cinematográfica de su país y culpable de obras maestras de corte experimental como la emocionante Tatsumi, una vida errante (2011). La premisa dada por la productora exigía que cada episodio se desarrollara en una nación distinta y, por tanto, la acción girase en torno a una criatura sobrenatural propiamente autóctona. El espectador agradecerá esta decisión al generar una gran variedad de espacios y atmósferas dentro de la serie, lo cual no es óbice para que nos embargue la sensación de una espiritualidad compartida, situada en las antípodas del mundo de las mentalidades occidental (Hearn, 2011:13).

La producción cosechó un éxito inesperado tanto en Asia como EE. UU, por lo que HBO ha confirmado una segunda temperada para 2022. Mientras llegan los siete nuevos episodios, nosotros realizaremos un repaso de los seis primeros con el objetivo de estudiar su forma -el manejo técnico y cinematográfico- y su fondo -es decir, el porqué de aquellos mitos y su plasmación en pantalla-. Empecemos.

\section{El amor de una madre}

El primer capítulo representaría a Indonesia y estuvo dirigido por Joko Anwar, antiguo crítico de cine que dio el salto a la fama internacional tras rodar Los hijos de Satán (Pengabdi Setan, 2017), remake de Satan's slave (Gautama Putra, 1982), film de horror más taquillero de la historia de las islas, y a su vez reescritura de la mítica Phantasma de Don Coscarelli. La historia da comienzo cuando Marni y su hijo se ven obligados a pernoctar en una mansión después de ser desahuciados por impago. Tras percibir una extraña atmósfera en la casa, la

\footnotetext{
${ }^{1}$ Entiéndase como cuento de fantasmas japonés moderno, donde la interacción de los espectros con la tecnología y las nuevas circunstancias sociales del país adquieren total protagonismo.
} 
mujer descubre una estancia repleta de niños raquíticos y desnudos, los cuales tan solo consiguieron sobrevivir a su encierro alimentándose de sus propias heces. Incluso después de que la policía devolviera a los pequeños a sus familiares, Marni siguió notando una malsana sensación en su entorno durante los días posteriores, al tiempo que la conducta de su hijo, Jodi, se hacía cada vez más atípica. Mientras tanto, un conocido parasicólogo sugiere en un programa de TV que los "niños del ático" fueron víctimas del wewe, una entidad espectral que robaba a los hijos no queridos o desatendidos por sus familias. Finalmente, la protagonista se percató de que aquel espectro manipuló sus pensamientos -verdadero motivo del aparente mal comportamiento de Jodien una estrategia que buscaba el desapego de la madre hacia el hijo y su ulterior rapto, entre otros episodios traumáticos Tras una voluntaria estancia en el psiquiátrico, Marni regresa al ático de la mansión y encuentra allí a su vástago desaparecido, instante en que se enfrenta a la entidad, sin miedo y dispuesta a prevalecer sobre ella. El wewe, de apariencia abominable, se acerca inquietantemente hacia ellos, pero en vez de mostrar hostilidad se funde en un sereno abrazo con la familia.

La leyenda de la wewe gombel no es exclusiva de Indonesia, sino que está también muy extendida en el imaginario de su vecina Malasia. Originaria de Java, en ella se cuenta cómo una mujer estéril hubo de soportar que su marido engendrara un sinfín de hijos bastardos por la zona, hecho que la llevó de manera irremediable al suicidio. A pesar de que la religión predominante en Indonesia sea la musulmana, la notable influencia del budismo en aquella sociedad implica que, cuando alguien muere en el fragor de una emoción desaforada, su espíritu se mantenga anclado en nuestro plano de existencia, para así remediar el motivo de su tormento. En el caso del wewe, ante la imposibilidad de cuidar a hijos de su propia sangre, raptaba a aquellos no deseados por sus familias, en aras de satisfacer sus frustrados instintos maternos. Si bien el espectro presenta cierto aire vengativo, casi nunca ejerce mal alguno sobre las criaturas que intenta cuidar, pues hablamos de un ente enquistado entre dos mundos, incapaz de dar alimento o paliar la enfermedad de niños expuestos al clima del bosque, donde según la tradición oral suele morar el monstruo. 
En cuanto a la representación del mito, Joko Anwar ha sido extremadamente cuidadoso a la hora de plasmarlo en la pequeña pantalla. El impactante fotograma de la ajada multitud de infantes observando en la oscuridad a los protagonistas -como si fuera un pequeño ejército de hermanos de Toshioapunta a esa negligencia de la entidad por criarlos sin el más mínimo conocimiento sobre cómo hacerlo. En efecto, la humana preexistente al wewe abandona la vida y con ello su ser social, olvidando toda regla cívica o de convivencia, hasta llegar a ser una masa de energía puramente instintiva. Esta connotación animalística se ve plasmada en los rasgos rapaces de la criatura, con manos grotescas y alargadas como las de un ave. Dicha analogía se observa en los "nidos" creados por el espectro, según la cultura popular situados en las copas de los árboles, y para la ocasión en el ático de un edificio abandonado, lugar en las alturas e igualmente aprovechable para el asentamiento de las aves en un contexto más urbano. La relación con el ababil del Corán², pájaro benefactor pero potencial transmisor de enfermedades como se demostró con los abisinios- es factible en el caso del wewe, lo cual termina de bocetar un fantasma complejo y de intrincado alineamiento moral.

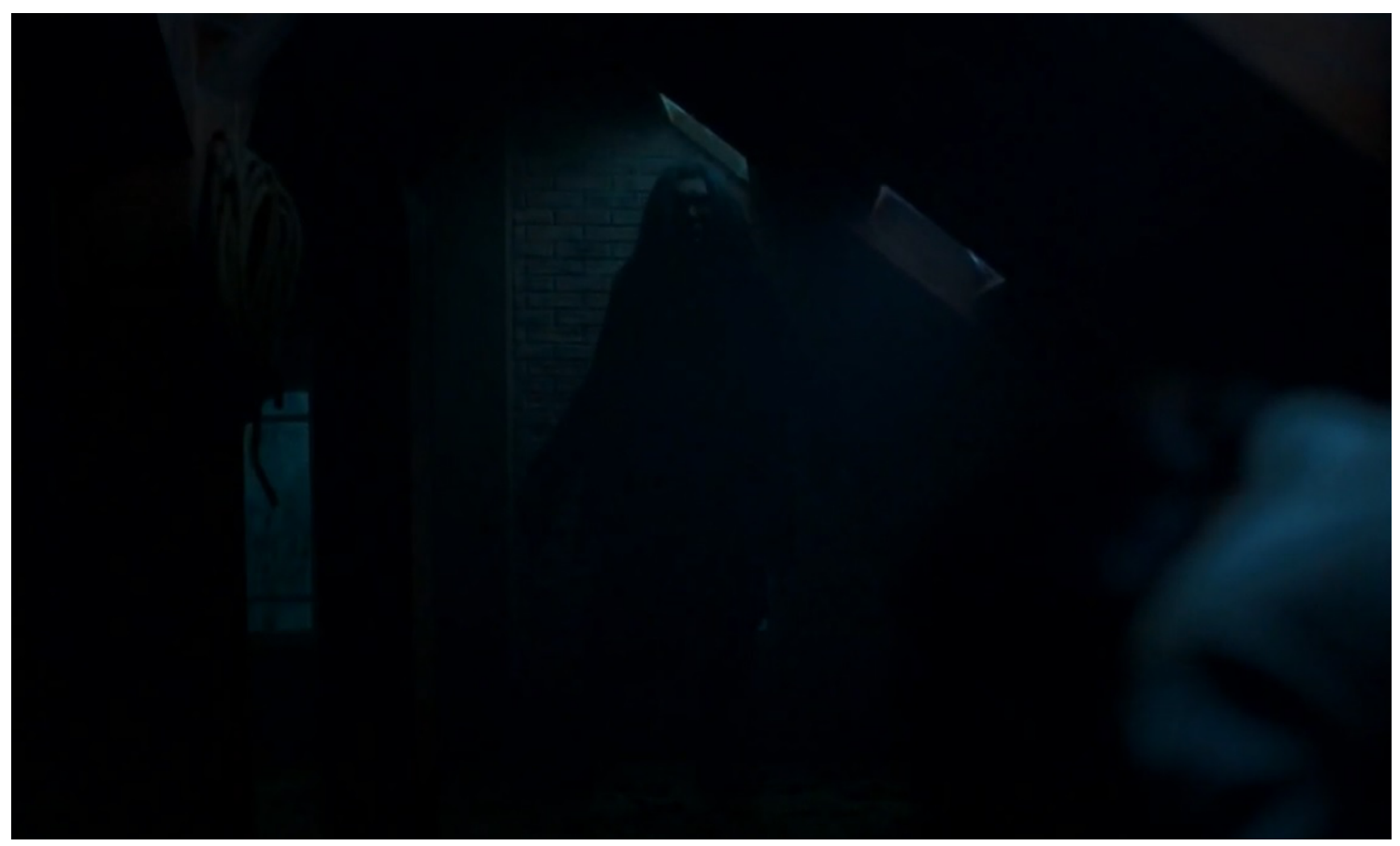

F1. Folklore (HBO: 2018).

2 Sura 105: Al-Fil (El Elefante). 
Ya refiriéndonos a la labor de Anwar como cineasta, su cinta administra una fotografía por encima de la media en este tipo de producciones menores, hallándose vertebrada por un evidente simetrismo visual. El uso del color supone un baile de verdes y azules bajamente atemperados, que en ocasiones contrastan en fondo de campo con texturas cálidas provenientes de focos de luz. Tampoco deja de destacar su manejo del desenfoque y la oscuridad como eventuales carriles narrativos, como sucede en el primer encuentro con los niños o durante el agón final contra el wewe. En conjunto, sin siquiera rayar el cuidado visual de los principales films de terror de los últimos años, A mother's love supera ampliamente la calidad estándar común a este tipo de series.

\section{Tatami}

Paradójicamente, el capítulo correspondiente a Japón quizá sea conceptualmente el más extraño de toda la antología. La cuestión no deja de ser relevante porque el J-horror es precisamente el factor que vino a insuflar vida a este proyecto, aunque por otro lado podría haber resultado decepcionante otro producto más con mujeres fantasmales de largas cabelleras negras cubriendo su rostro. La voluntad por desmarcarse del estereotipo de terror nipón puede entreverse desde la misma elección de su director, Takumi Saito, un ex idol de éxito a finales de 90's que reorientó su carrera hacia la industria del cine. De hecho, pocos meses antes del estreno de Folklore, haría amistad con Eric Khoo en el rodaje de Una receta familiar (2018), con Saito en el rol de protagonista principal, hecho que acaba por encajar su participación en este proyecto.

Para la ocasión, un periodista de sucesos afectado de sordera y llamado Makoto (Kazuki Kitamura) vuelve a casa debido al inesperado fallecimiento de su padre. Una vez allí, comienza a experimentar recuerdos inquietantes de su niñez, además de descubrir en una habitación apartada un tatami jalonado con manchas de sangre. La presunta madre de Makoto, Yoshiko, le explica que su cuñado y supuesto tío -en realidad padre biológico-, fue asesinado en disputa por una herencia años atrás, y que su supuesto padre (pero tío real), Tsukasa, nunca se recuperó del todo de la experiencia, quedando postrado en una cama desde entonces. De repente, la reciente avalancha de información 
lleva al periodista a recordar una traumática experiencia reprimida, ya que sobrevivió a aquella masacre de la familia Shinomiya, origen del trauma y casusa de su pérdida de audición. A medida que estos recuerdos iban desvelándose con su presencia en la casa, la habitación del tatami ensangrentado iba cobrando mayor fuerza en su mente. Ya durante el desenlace, tanto la falsa madre como el protagonista desembocaron entre aquellas cuatro paredes, momento en que ella intenta asesinar a su hijo adoptivo por haber averiguado el oscuro origen de la fortuna familiar. Sin embargo, justo cuando la mujer alzó el cuchillo, el tatami empezó a sangrar, abriéndose en una enorme cavidad sanguinolenta que fagocitó a la "madre" de Makoto.

Condenado el típico yūrei al olvido más flagrante, el protagonismo del capítulo recae sobre otro de los mitos sobrenaturales y pseudorreligiosos más importantes de Japón: el tsukumogami (Míguez, 2021: 119). Se trata de una de las tipologías de yōkai más populares en aquel país, compartiendo pedestal con el kappa, o duende de río; el tengu, híbrido entre cuervo y humano, experto en artes marciales; y la rokurokubi, mujer de cuello largo. La explicación de la sobrenaturalidad de ciertos objetos en la cultura nipona (sandalias, paraguas, lámparas, etc.) se explica en función de un atisbo de conciencia latente que despierta ante el llamamiento vivencial, el cúmulo de energías positivas y negativas, o el mero transcurrir de las décadas. Para remediar el problemático nacimiento del yōkai existen ciertos ritos relacionados con la renovación y la limpieza shintoista, pues normalmente hablamos de utensilios abandonados que acumulan suciedad. Por tanto, la sangre que empapó el tatami lo fecundó de enfermedad e inmundicia, originando un ente vengativo al calor del oprobio, la venganza y la desesperación.

En un vestigio casi inconsciente, aún hoy día los japoneses renuevan el trastero en fin de año, ya sea deshaciéndose de objetos inservibles, o bien limpiando aquellos que aún puedan ser reutilizables. Llama la atención, eso sí, que el tatami se vengue tan solo de Yoshiko, dejando traslucir que parte de la esencia del padre de Makoto aún pervivía entre las fibras. No obstante, este pensamiento nos alejaría del canon demonológico japonés, puesto que los yōkai objeto nacen alcanzando una noción propia de sí mismos y no tras ser poseídos por otro espíritu. 
Por otro lado, la elección de Takumi Saito a la hora de prescindir del típico fantasma y presentar un ente distinto se nos antoja muy acertada, lo cual se suma a un manejo sorprendente de las imágenes y la narrativa, al menos para un director de no tan largo recorrido tras la cámara. La cinta explota el gusto por el alto contraste en el tratamiento visual, siendo común la luz dura con poca o nula transición en las sombras. Este detalle se observa desde el mismo comienzo, cuando el protagonista fotografía un apartamento abandonado lleno de muñecos de paja y colmado de suciedad, que nos evoca directamente a la vivienda usada por Takashi Shimizu en Ju-on (2002).

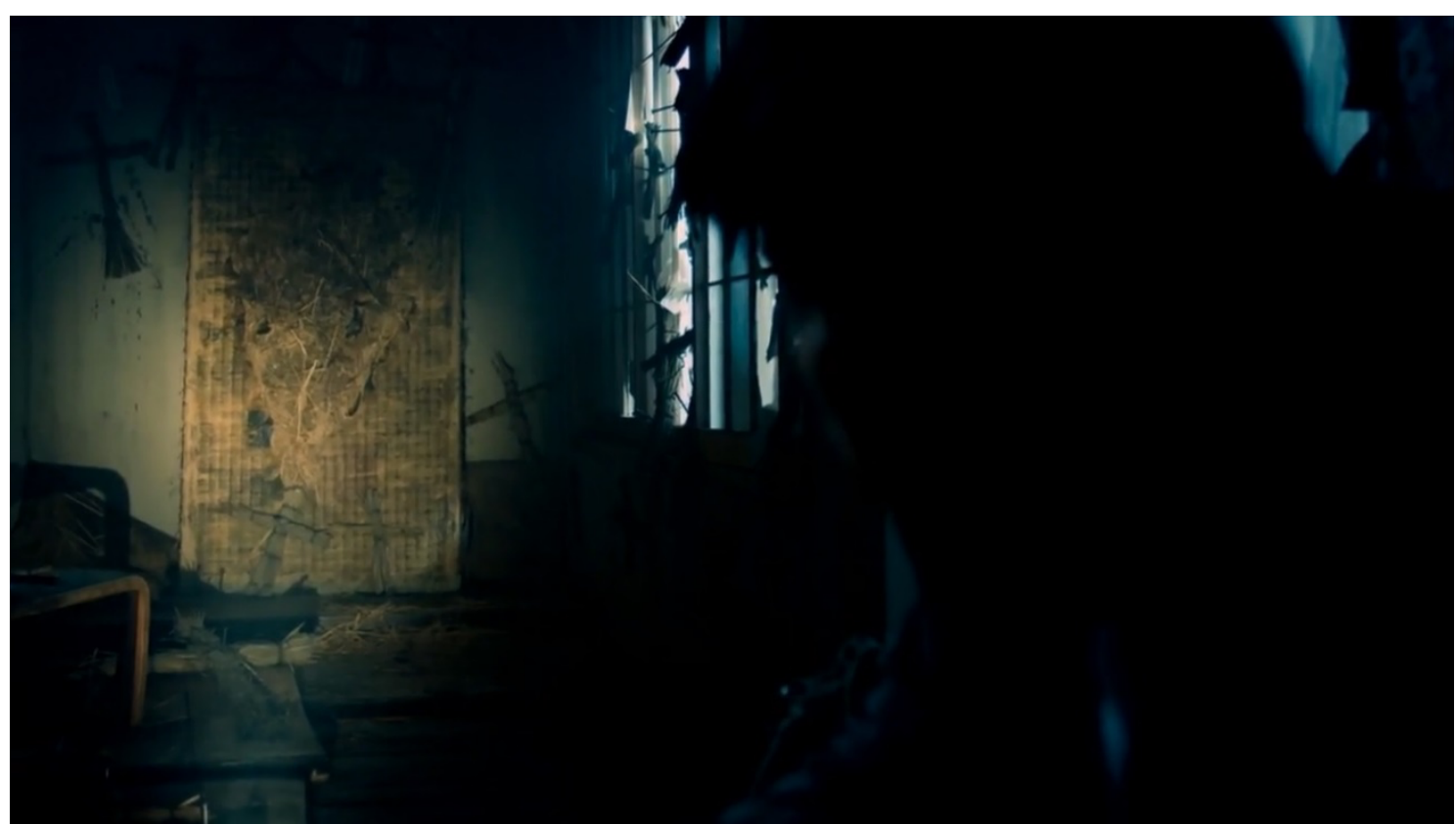

F2. Folklore (HBO:2018)

El capítulo destaca además por su mutismo, en un aprovechamiento óptimo de la discapacidad de su protagonista, para dar cabida a un paisaje sonoro de corte experimental, con levísimos toques de industria y tendencia al surrealismo. Como contrapartida está su montaje, a juicio de algunos críticos confuso por el excesivo uso del flashback, pero que a nuestros ojos tan solo contribuye a aumentar la abstracción del cuento, en sin duda una estrategia armónica y beneficiosa para el conjunto. Muy estimulantes en este sentido resultan las sucesivas apariciones de Makoto siendo niño, quien, como un fantasma del pasado, intentaba transmitirle a su "yo" futuro cuál era la realidad de su situación. En una de ellas, el pequeño aparece encima del tatami señalando a la "cuarta pared", en un plano bellísimo marcado por los halos de luz que se 
filtraban desde unos ventanales, y que dialoga sin tapujos con algunos fragmentos del video maldito visto en Ringu (1998). En síntesis, es precisamente esta voluntad de homenajear a los tótems del género sin confrontar con la renovación y la frescura, el motivo de que Tatami sea no solo uno de los mejores capítulos de la serie de Eric Khoo, sino también una de las más interesantes propuestas del terror japonés en el último lustro.

\section{Nadie}

Desde Singapur Eric Khoo nos presenta el mito de la Pontianak, un tipo de fantasma a medio camino entre el jiang shi chino -por sus atributos vampíricosy la ubume japonesa (Ayala, 2012: 85). El relato comienza con la salvaje violación a una menor por parte de varios hombres en medio del bosque. Después de quedar encinta debido a los reiterados abusos sexuales, los agresores decidieron acabar con la niña introduciéndole un clavo en la nuca, según el conocido rito surasiático para exorcizar espíritus. Pasado un tiempo sin determinar, el cadáver es descubierto por varios obreros que pretendían construir un resort de lujo en aquella zona. Por dictamen del dueño de la corporación, el capataz ordena a su vez al trabajador Peng (Li Wen Qiang) no dar parte a las autoridades y quemar el cadáver, pues si la noticia llegaba a los medios se correría el riesgo de que nadie quisiera invertir en el complejo hotelero. La cuestión es que, en el último momento, Peng se compadece de la joven por poseer una apariencia semejante a la de su hija, llegándole incluso a extirpar el clavo de su nuca bajo el deseo de inhumar el cuerpo sin mácula de violencia alguna. Como el lector imaginará, la extracción del objeto punzante ocasionó el despertar del ente vengador, siguiendo una serie de violentísimos asesinatos entre los conspiradores. Durante la conclusión del mediometraje, en un interesante juego de miradas, la pontianak derrama una lágrima mientras Peng admira, melancólico, una fotografía de su hija. Entonces el fantasma sonríe y parece descansar en paz. 


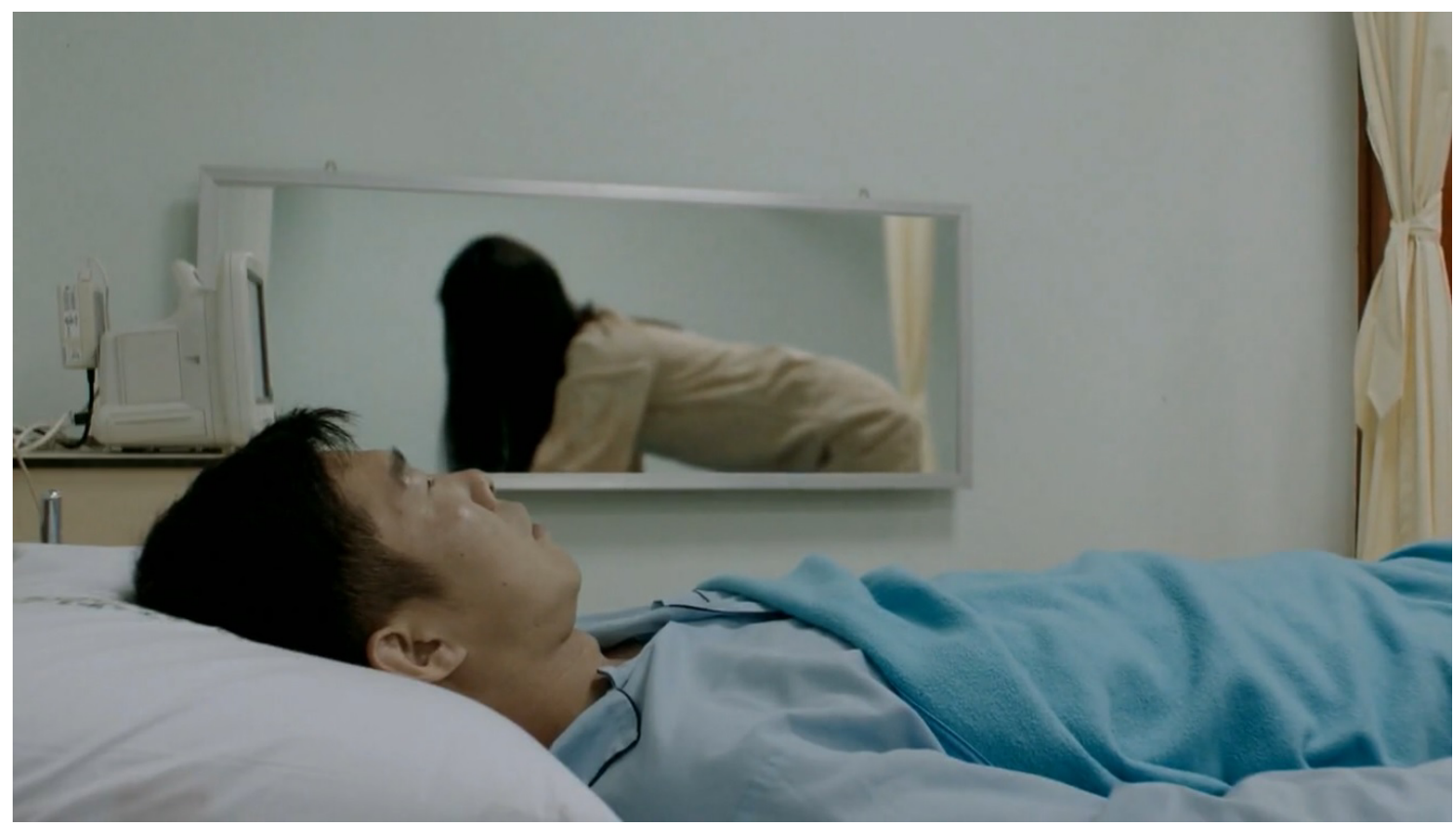

F3. Folklore (HBO:2018).

Nos hallamos sin duda ante el relato más convencional de entre los que componen la antología, llegando a ser un remedo de la típica venganza fantasmal femenina tantas veces repetida en filmes como Shutter (Banjong Pisanthanakun, 2004) o la misma Ringu. A lo largo de nuestra trayectoria hemos procurado subrayar la evidente vindicación feminista subyacente en este tipo de historias, puesto que al final hablamos de mártires que persiguen, aunque sea post mortem, reequilibrar un mundo construido por y para hombres. Técnicamente el mediometraje es funcional y sencillo, y podríamos decir que carecería de interés de no ser por ciertos particularismos culturales, como el mismo uso del clavo, muy extendido en el esoterismo de Malasia, Singapur, Tailandia, China o algunas zonas de la India (Theroux, 1977: 56). Dependiendo del lugar, el metal de la nuca podría ser un medio nigromántico de dominio sobre el finado o bien el impedimento para que surgiera una eventual consciencia a partir de la carne muerta.

Otra novedad de la cinta respecto al canon narrativo asiático sería el proceso selectivo del espectro, que para la ocasión no extermina por exterminar, sino que es capaz de sentir compasión y empatía, precisamente, hacia la persona que le extrajo el clavo de la nuca. Rara avis dentro de un género en el que normalmente la maldición se esparce más allá de los individuos implicados, pues si estos se llegasen a relacionar durante el periodo de embrujo u hostigamiento 
espectral, aquellos contactos podrían llegar a ser potencialmente nuevas víctimas del pontianak o espíritu que fuere.

No podemos concluir sin mencionar el gran parentesco entre nuestra aparición y la ubume, cuya esencia también se conforma en torno a un bebé que no nació o no pudo crecer. Como se hace notar en la conocida obra kabuki Tokaido Yotsuya kaidan, la ubume puede llegar a demostrar un ansia de venganza notable, aunque sin llegar a las cotas del onryō3. Ineludible es también la referencia a Nang Nak, leyenda tailandesa sobre un hombre que convive sin saberlo con su esposa e hijo muertos. En este caso, el pueblo consiguió contratar a un exorcista que conjura al espectro tras exhumar su cadáver y martillearle una punta de hierro en el cráneo.

\section{Pop}

Casualidad o no, desde Tailandia llega el cuarto de los episodios, un número especial si hablamos de terror asiático, entendiendo la marcada tetrafobia imperante en aquella región ${ }^{4}$. Guionizado por el mismo Eric Khoo y dirigido por Pen-Ek Ratanaruang (Invisible Waves, 2006), el capítulo está dotado con el don de la excepcionalidad, merced a su particular blanco y negro, cuando no flirtea abiertamente con el cine underground. Lo anterior llama poderosamente la atención porque la serie en ningún momento pretende ser alternativa-al menos, técnica y narrativamente- por lo que Pop constituye una preciosa gema escondida a descubrir.

Manop (Nuttapon Sawasdee), un bloguero especializado en sucesos escabrosos asiste a cubrir el extraño asesinato de un alto ejecutivo estadounidense en Bangkok. Una vez tomó algunas fotos en la escena del crimen, exploró las inmediaciones del lugar hasta introducirse en un cobertizo. Allí conoció a alguien (Parama Wutthikornditsaku), en apariencia un simple y andrajoso indigente, pero que a la postre resultó ser un fantasma caníbal conocido como Pop. La naturalidad -y naturalismo- con que se expresaba el

\footnotetext{
${ }^{3}$ Se trata del fantasma vengativo por antonomasia en Japón. Sadako, Kayako o Isora son claros exponentes de la tipología.

${ }^{4}$ Cuatro es símbolo de mal agüero en Asia porque en chino el número se pronuncia igual que el término "muerte". El hecho de que la tendencia se mantenga en países con idiomas distintos responde a la aplastante influencia del gigante asiático en el resto del continente.
} 
espectro invitó a Manop a realizarle una improvisada entrevista, que desvelaría la forma en que murió, o cómo devoró el cadáver que yacía en el dormitorio principal de la vivienda. Pob estaría muerto, pero no estaba anticuado; conoce la importancia de las redes sociales y desea dar a conocer su historia. Manop, desconcertado ante la situación bizarre, rechaza la insólita petición en primera instancia, pero sugiere al fantasma que si le facilitara el número ganador de la lotería accedería a escribir la Crónica de Pop. La narración da a entender que Manop ganó el primer premio, si bien la enfermedad terminal de su madre seguía empeorando. El protagonista, al límite, propone una última oferta a su espectral interlocutor: si Pop salvaba de la muerte a su progenitora, Manop se ofrecería voluntariamente como alimento para el espectro. El capítulo se cierra con Pop sonriendo siniestramente, dándose por sobreentendido que aceptaba el trato.

El trasfondo mágico del Pop sobrepasa con mucho al del típico fantasma convencional. Su génesis podemos encontrarla en el espíritu de una flor que poseyó distintos cuerpos, para después involucionar en el interior de cada uno de ellos y alcanzar un frenesí antropófago. Es decir, si este espectro caníbal llega a poseer a un individuo devorará sus intestinos durante el sueño, en la línea del succubo o el íncubo, aunque eso sí, sin connotaciones sexuales de por medio. Hablamos, por tanto, de una sustancia espiritual afectada por un karma pasional y desmedido que, encarnación tras encarnación, va deformándose hasta llegar a ser algo grotesco.

A diferencia de lo mostrado en Folklore, el pop mitológico suele ser mayoritariamente femenino, y es espeluznante cómo esta creencia condiciona aún a día de hoy el comportamiento de algunas regiones rústicas en el país. De hecho, el pop ha servido a lo largo de los siglos como excusa para crear réprobos, apestados, o parias sociales, que son expulsados de una comunidad presuntamente por estar muertos, aunque en realidad fueran otras las razones para hacerlo (Brice, 2018: 34). Una apariencia enfermiza podría ser motivo suficiente para el destierro -por temor al posible contagio de alguna enfermedad- ergo estos lémures se han imaginado esqueléticos, con grandes ojeras y rebosantes de llagas en el cuerpo. Así las cosas, el proceso de maquillaje y caracterización realizado para el actor Parama Wutthi puede definirse como un all in en toda regla. 


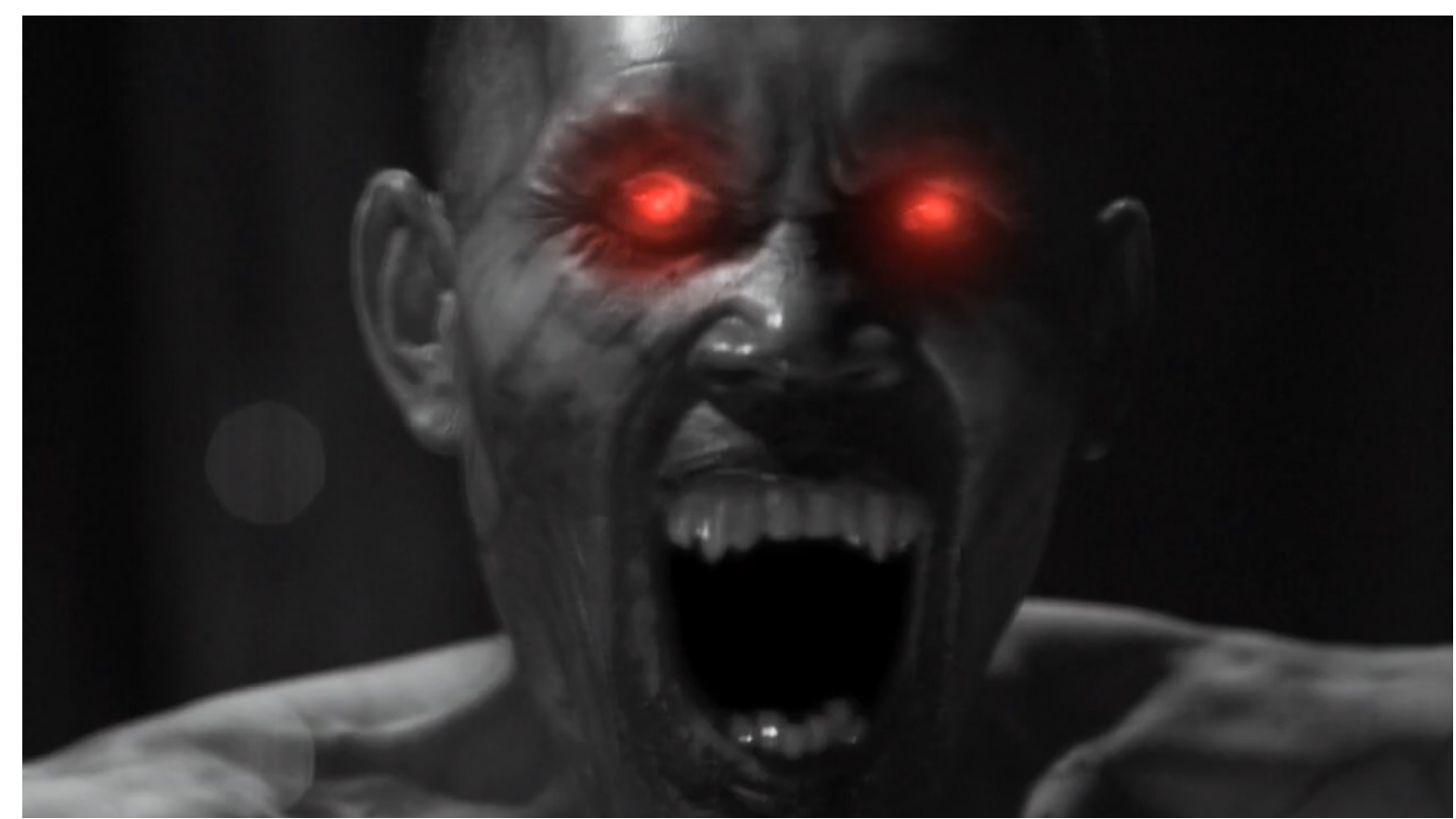

F4. Folklore (HBO:2018).

Pob nos resulta de largo el mediometraje más genuino de Folklore, constituyendo un efectivo híbrido entre cine noir, T- Horror, y una inesperada dosis de humor lynchiano. Es envidiable la habilidad necesaria para empastar los tres géneros, en una a priori difícil búsqueda de suspense, comicidad y pavor. Y podemos decirlo abiertamente, se consigue: el espectador sentirá una incómoda familiaridad cuando imagina departir con Pop, puesto que después de cada frase amable, durante cada pausa, aunque sea durante un solo instante, se vislumbra al verdadero depredador que acecha tras esos ojos huecos. En última instancia, no negamos que la trama de este episodio pueda resultar surrealista, ridícula o anticlimática, si bien su trasfondo nos recuerda uno de los aspectos más perturbadores de la condición humana: la autoconsciencia y su inherente deseo de perpetuación -da igual que proceda de alguien vivo o muerto- invitan a prevalecer sobre el prójimo. Sea cuales fueren las consecuencias.

\section{Toyol}


Dirigido por el semi desconocido cineasta Ho Yuhang, el capítulo da comienzo mediante un prólogo en el que una madre adolescente y su bebé mueren en una desgraciada explosión de gas. En la siguiente escena, en medio de la noche, una mujer de blanco desentierra los restos de la criatura con el objetivo de conjurar un Toyol, espíritu con la capacidad de atraer la riqueza a su dueño. Tiempo más tarde, un miembro del Parlamento malayo (Bront Palarae), espera averiguar la causa de que la totalidad de peces de una prolífera zona fluvial mueran sin explicación alguna. Tras intentar remediar infructuosamente la debacle económica por medio de un chamán, el político conoce a una misteriosa hechicera (Nabila Huda) quien le resulta vagamente familiar. Pronto, ambos personajes comienzan una relación romántica, a pesar de la repentina muerte de Zul, principal consejero del protagonista y contrario al enlace con aquella mujer.

La situación mejora y el ahora matrimonio prospera hasta el punto de que ella quedó embarazada, instante en que el protagonista comienza a padecer sueños perturbadores sobre un bebé monstruoso. Una noche, empapado en sudor, Zul descubre a una espantosa criatura, semejante a un niño deforme, alimentándose en la cocina de la planta baja. El incidente llevaría a su esposa a revelar por fin la verdad: el padre de Zul mantuvo una aventura extramatrimonial con la madre de la hechicera, pero cuando esta cumplió los quince años sería violada en reiteradas ocasiones por su propio progenitor. Una vez muerto, la mujer decidió realizar el rito toyol para así ganar poder y vengarse de la familia de su medio hermano, único superviviente del clan. Traumatizado por la revelación, Zul acaba en un psiquiátrico, siendo visitado esporádicamente por su hermana/esposa y su sobrino, quien sádicamente le suele mostrar el mismo muñeco con el que jugaba su otro hijo fallecido.

El Toyol es una entidad muy conocida en el marco de la magia negra del sudeste asiático. Eric Khoo, en su labor de guionista, ha planteado en pantalla cómo surge este ser, si bien ha dejado a un lado algunos aspectos del mito que podrían haber resultado demasiado disturbing, sobre todo en un formato alejado del cine extremo y el ultragore. Y es que el dominio sobre el Toyol exige sacrificios de distinta índole, pasando por pequeños animales hasta incluso otros bebés, dependiendo de lo que el brujo ansíe conseguir concretamente. Además, la relación entre la hechicera -o bomoh- y el monstruo se "asemeja : 
con todas las comillas que podamos ponerle, a la de una madre y un hijo. Se cree, en efecto, que el Toyol succiona la sangre de su dominadora a través de los pezones, en una parodia maligna de la lactancia materna. Por otro lado, el nacimiento de un ser aterrador que sofoca los propios deseos a cambio de una relación retribuyente nos evoca al inugami japonés, solo que, en vez de un monstruoso niño humano, el genio complaciente pasaría a ser el fantasma de un perro. En ambos casos las entidades estarán atentas a cualquier fallo en los ritos de control para así acabar con sus dueños y ser libres.

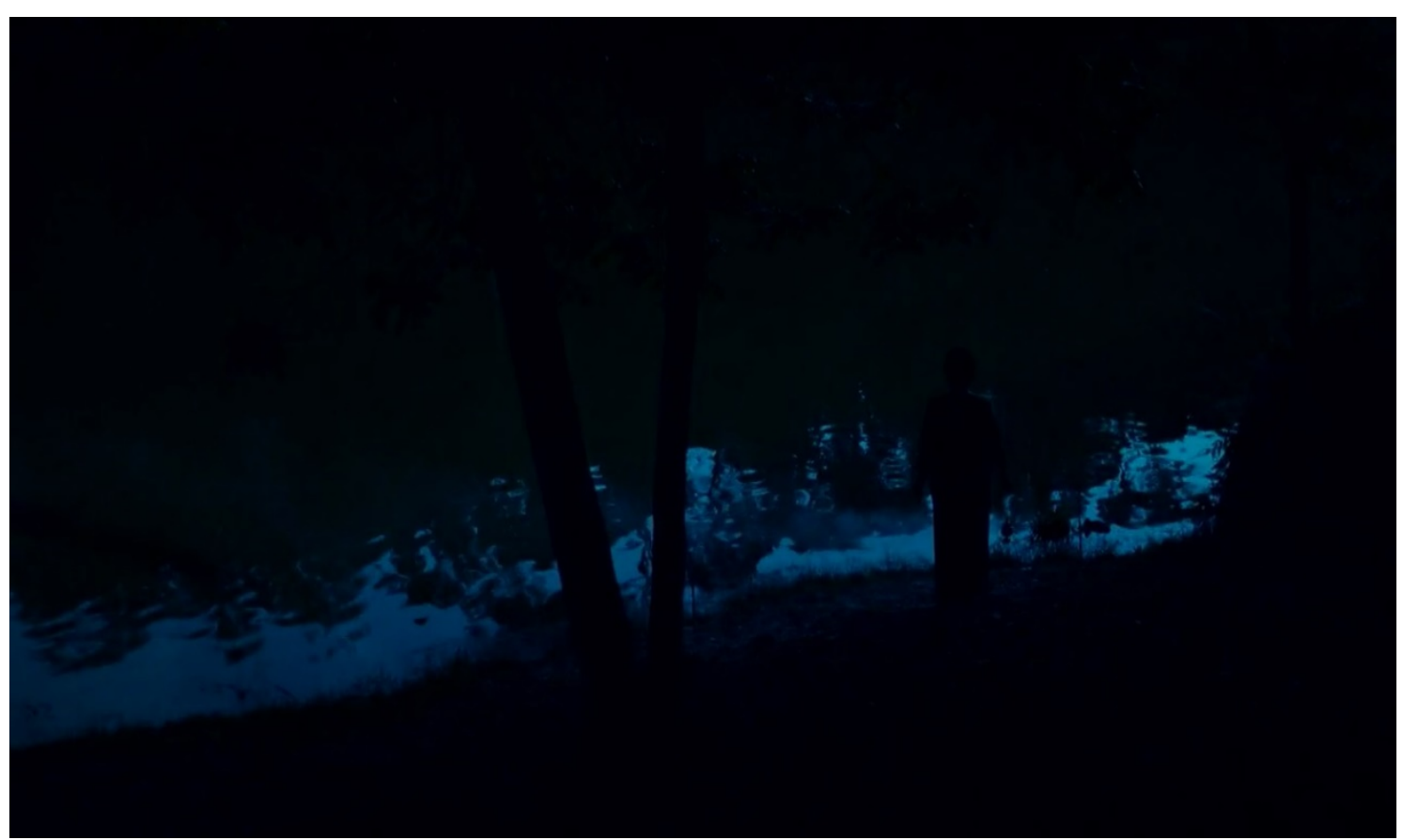

F5. Folklore (HBO:2018).

A diferencia de como sucede en el resto de los capítulos de Folklore-casi todos sencillos en buen término, cuando no lineales- Toyol presenta una estructura narrativa ciertamente compleja para sus escasos cuarenta y cinco minutos. Yendo más allá, podríamos afirmar que lo más terrorífico del capítulo no sería el pequeño monstruo en sí mismo, sino el ansia de venganza por parte de la hechicera. Es ella el motor de todo espanto surgido del film, y sin necesidad de planos explícitos o impactantes; tan solo el suave y desconcertante gesto de su rostro invita a pensar que su compañía no es recomendable, si bien prevalece su indudable magnetismo y poder de seducción. Junto a la actuación del joven niño de El amor de una madre, Muzakki Ramdhan, estamos ante la mejor interpretación de toda la serie. 
Hay algo de Medea y Edipo Rey en Toyol, Tragedias Griegas donde las féminas no salen demasiado bien paradas. Es conocido que para el mundo musulmán la mujer es un elemento periférico o complementario, estando supeditadas a los intereses masculinos en todo momento. Por si fuera poco, la potente presencia budista no hace sino empeorar la situación para ellas, puesto que bajo la cosmovisión de la mayoría de ramas dhármicas, la hembra es un estadio inferior en el ciclo de renacimientos o samsara (Cornu, 2004: 414). Es decir, para llegar a renacer en un hombre se ha tenido que ser, previamente, una buena vaca y una piadosa mujer. Esta desventaja moral ha sido caldo de cultivo a la hora de crear arquetipos históricos de villana en toda Asia, de las cuales pueden ser muestra la emperatriz china Cixí o la esposa del general Nobunaga, Nôhime, ambas tildadas de brujas, ya sean literales o figuradas.

Tampoco hemos de obviar que la historia de Toyol implique a un alto cargo del gobierno. No la sufre un granjero de alguna zona perdida del país, ni siquiera cualquier individuo anónimo en la soledad de su vivienda unifamiliar, sino alguien aparentemente preparado, ducho en el manejo de idiomas y el conocimiento de culturas ajenas. El factor no es baladí porque nos habla de las profundísimas creencias en el esoterismo, la magia y el poder de los espíritus en sociedades superficialmente modernizadas. Malasia, por ejemplo, se halla tan solo ocho lugares por debajo de España en PIB, y su capital legislativa, Kuala Lumpur, presenta unas dimensiones similares a las de Madrid. Sin embargo, allí es común el oficio de chamán, bomoh, o curandero, siempre prestos a "remediar" los problemas del día a día, y llegando a poseer establecimientos en zonas céntricas al lado de peluquerías, tiendas electrónicas o restaurantes de haute cuisine. El hecho no es privativo de Malasia, siendo China -en la práctica la primera potencia mundial- el lugar donde más proliferan los exorcistas taoístas, a los cuales se accede tanto para la óptima inauguración de rascacielos como para la consecución de un amor no correspondido. Y siendo de esta forma ¿̇cómo no va a cobrar importancia el mundo de lo sobrenatural en aquellos países?

Finalmente, la película viene a rescatar para Asia un cliché más o menos asentado en el horror universal: el bebé monstruoso. Desde La semilla del diablo (Rosemarie's baby, Roman Polanski, 1968) pasando por ¡Estoy vivoi (It's Alive, Larry Cohen, 1974) o Tu madre se ha comido a mi perro (Braindead, Peter 
Jackson, 1992), todas evocan el miedo atávico hacia la eventual malformación del feto, o incluso por la violencia y crueldad de un ser sobrenatural despojado de cualquier tipo de moral o empatía. Y es que al final, acaba de nacer.

\section{Mongdal}

En lo que llevamos de siglo XXI el coreano ha progresado hasta adelantar al más reconocido cine japonés. Por supuesto, la opinión es tan subjetiva como todo lo relacionado con lo artístico y depende de los gustos personales y de la formación de quién observe. Sí sería más ecuánime afirmar la paulatina pérdida de clasicismo en el celuloide nipón a partir de 2000 -más allá de algunos pocos cineastas como Yoji Yamada o, en cierta forma, Hirokazu Koreeda- y un acercamiento cada vez mayor a los usos propios del manganime, ya sea en lo estético o en lo narrativo. Mientras tanto, directores como el recientemente fallecido Kim Ki Duk (Primavera, verano, otoño, invierno... y primavera), Park Chan-wook (Oldboy) y Bong Joon-ho (Memories of Murder) sentaban las bases en un mágico 2003 para todas las películas extraordinarias que en Corea estaban por venir, incorporando al ya consabido lirismo japonés un mayor cuidado visual y, sobre todo, un ritmo más acorde al gusto del espectador promedio. De ahí que la propuesta de este país sea apriorísticamente una de las más interesantes de la lista, considerando además el sinfín de cintas destacadas surgidas al calor de Sadako y el neo kaidan, como fueron Phone (Pon, Ahn Byeong-ki, 2002) o Dos hermanas (Janghwa Hongryeon, Kim Jeewoon, 2003).

El interesante Lee Sang-woo, ayudante de cámara de Kim Ki Duk en varias de sus producciones, es el encargado de este capítulo. Tal vez sea el cineasta con una carrera más asentada dentro del roster de Folklore, estando avalado por entre otras películas notables, Mi madre es una puta (Uhmmaneun Changnyeoda, 2009) o Mi padre es un perro (Abeojineun Gaeda, 2010), en las cuales una mujer de sesenta años mantiene a su hijo ejerciendo la prostitución y un padre abusa de sus tres niños, respectivamente. Lejos del aire softcore de otros episodios, y dada la trayectoria creativa de Lee, Mongdal sea probablemente el cuento más espeluznante de todos, indagando en sutilezas y propuestas escénicas no vistas hasta ahora. 
La acción gira en torno a Dong-Joo (Jeong Yun Seok), un joven caprichoso y afectado por graves accesos de ira. Él está absolutamente obsesionado con una bella compañera de clase llamada Seo-Woo (Choi Jeong-Eun), pero ella no le corresponde por ser el "rarito" de la clase. Pese a que la madre de DongJoo -precisamente la directora del centro de estudios- intentaba rectificar la conducta de su hijo de todas las formas posibles, este se convirtió en un stalker de Seo-Woo, hasta el punto de llegar a acosarla en su propia casa. Cuando la situación se tornó insostenible, la joven increpó a Dong-Joo haciéndole ver que le repugnaba e instándole a no interaccionar nunca más con ella. Ante ese rechazo, el joven se acostó en su cama junto al busto de un maniquí espantoso que representaba a Seo-Woo, para acto seguido arrojarse al embalse del pueblo. Una vez muerto, el espíritu del adolescente siguió molestando, motivo por el cual su madre contrató los servicios de un chamán.

El sacerdote muísta detalló a la directora del colegio que su hijo se había transformado en un mongdal, un espíritu virgen condenado a vagar por no haber conocido el amor y el contacto carnal. La solución dada por el monje resultó de lo más irregular: la madre debería desenterrar el cadáver de alguna joven y con ella realizar un ritual de enlace, en aras de conseguir apaciguar el sufrimiento del mongdal. Desgraciadamente, el espectro se apareció ante su madre llorando porque no soportaba a su nueva esposa, exigiéndole que le procurara el casamiento con su querida Seo-Woo. Enajenada, la directora del colegio se vale de su influencia para invitarla a su casa y a continuación asesinarla. El impasse de tiempo hasta la llegada del exorcista encargado del rito se convirtió en un infierno, pues el fantasma de la niña se aparecía constantemente ante su asesina. Cuando llegó, el religioso, escandalizado por aquella muerte innecesaria, se negó tanto a celebrar el matrimonio como a exorcizar al espectro de Seo-Woo, por lo que la madre se vio obligada a convivir con ella hasta su internamiento en un psiquiátrico. 


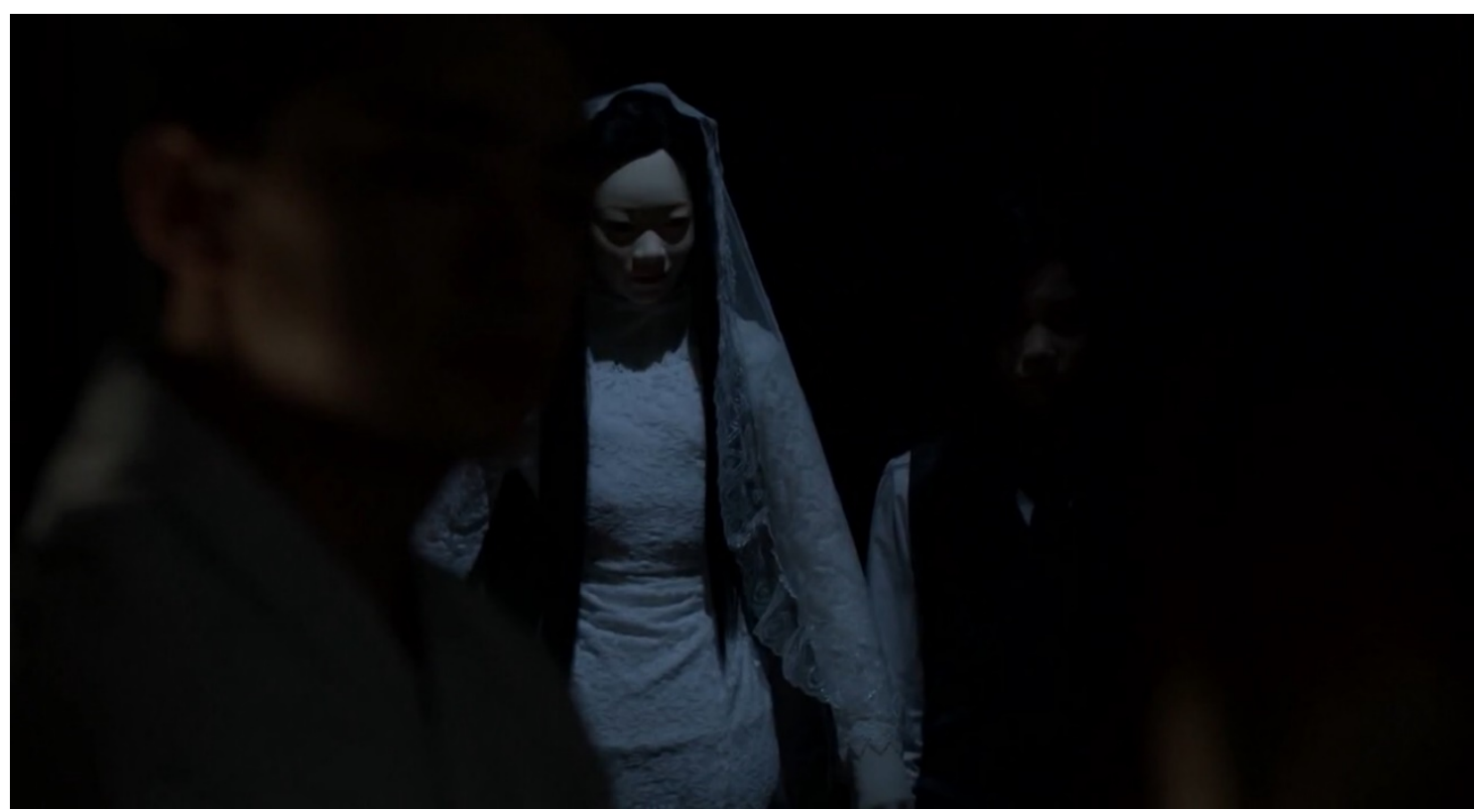

F6. Folklore (HBO: 2018).

Lee Sang-woo nos sumerge por única vez dentro de la antología en uno de los contextos arquetípicos del J\&K Horror: los colegios e institutos. A partir de los primeros noventa y el nacimiento de leyendas urbanas al estilo de Hanako -el fantasma de los baños-, estos contextos educativos constituyeron el escenario perfecto para las historias de terror, con sus solitarios y larguísimos pasillos cerrados al crepúsculo como inmejorable emplazamiento para las eventuales apariciones. Paradigma de lo anterior es la prolija saga coreana Whispering Corridors, o la enorme cantidad de videojuegos Survival Horror de ese tipo, ya sea ...Irui (Takara, 1998), o los más recientes A laberynth named school (Roi Games, 2015) y The night way home (Chilla's art, 2021). En todos ellos una alumna descubre algún secreto sobrenatural y debe solventarlo contrarreloj a riesgo de perder su vida.

Mongdal es interesante porque plantea problemas muy presentes en la sociedad de la despersonalización: el vacío a ciertos estudiantes, propagación del bullying, o conceptos superfluos como la popularidad. El daño acometido a nuestro protagonista por la suma de estos factores generó un ser espiritual anclado en nuestro mundo, obsesionado por alcanzar la aprobación femenina que nunca puedo conquistar en vida. El mediometraje, además, presenta en sociedad la desconocida religión muísta, de presencia extendidísima en Corea. Básicamente, el muísmo concibe un universo dividido en varios planos: el de los dioses, los espíritus y los hombres. Se trata por tanto de un sistema de creencias 
primitivo de tipo chamánico, donde el sacerdote actúa como intermediario entre los tres mundos intentando solucionar problemas. Aquí es donde deberíamos situar al exorcista de nuestra historia, quien acude con la intención de liberar al mongdal de su dolor. Para conseguirlo recrea un kut, ceremonia muy peligrosa de grandes similitudes con el bön nepalí, y que buscaba devolver al espíritu a su plano mediante el uso de fetiches, danzas y tambores. La reciente filmografía de terror coreana nos dejó una muestra espectacular de este tipo de ritos en El Extraño (Goksung, Na Hong-Jin, 2016), sin ningún atisbo de duda una de las producciones más complejas y notables dentro del género en Asia.

La propuesta cuenta con el activo de poner en escena un fantasma masculino como motor de la acción, si bien el espíritu de Seo-Woo es quien acaba acaparando todo el interés. Como decíamos anteriormente, la elegante gestión de los momentos de espanto, de alguna forma influenciados por cierto aire gótico, es tal vez la más sugestiva de todo el compendio. A nosotros nos resulta espeluznante, por ejemplo, el instante en que Seo-Woo se aparece ante su asesina a fondo de campo, triste y melancólica, ejerciendo presión sobre la consciencia más que encarnando una posible amenaza física. Por lo demás, una hija asesinada para que su espíritu quede cautivo por una entidad obsesiva y sexual podría resultar una de las peores pesadillas de un padre. Y eso es mérito de Eric Khoo y Lee Sang-woo.

\section{Coda}

Últimamente está extendida la idea de que el principal cometido de una narrativa de terror es provocar miedo. Se dice así, a bote pronto y sin cálculo, como si alguien de cincuenta años pudiera impresionarse por la aparición en pantalla de un asesino en serie o el monstruo del armario. Ergo en la misma sala de cine, justo cuando al encender las luces el típico espectador pronuncia "no me ha asustado", o incluso en comunidades de fans que denostan el género actual porque sus películas "no impresionan", se olvida el principal cometido de una obra artística: transmitir emociones. Nosotros añadiríamos al cocktail otro activo muy importante, como es la fiel descripción de una sociedad en concreto y su mundo de las mentalidades. En la época de la Globalización, de la tecnología y el mundo interconectado, este detalle en un tesoro a 
salvaguardar, puesto que hemos de tener claro que nos hallamos ante universos crepusculares, que se están acabando, al diluirse en la cultura mayoritaria impuesta por el capitalismo, EE. UU y la modernización.

Allá por el siglo XVII Matsuo Bashô pronunció, "denme un fantasma y os diré cómo son las gentes que lo crearon". No dijo ninguna mentira, porque los testimonios históricos se pueden adecuar a los intereses políticos del momento, pero resultaría imposible que un efluvio mitológico, fruto del subconsciente subjetivo, oculte la verdad si existe alguien capaz de decodificarla. Por consiguiente, aparte del noble objetivo del entretenimiento, Eric Khoo ha bocetado algunas de las grandes inquietudes asiáticas a través de sus espectros, al igual que la derrota de Polifemo frente a Ulises representó el auge de la oralidad frente a la fuerza de las armas en la Grecia del s. V a.C. De modo que si la Wewe Gumbel y la Pontianak nos hablan del sufrimiento femenino en un mundo absolutamente patriarcal; si el Pop o el Mongdal plasman el sufrimiento de aquellos que desean por encima de sus posibilidades; y si Tatami - Toyol nos advierten sobre la influencia del karma con base a nuestras decisiones pasadas; consideremos al fantasma como un inmejorable cronista de su tiempo, cuando no activista de causas que cada vez más agentes se arrogan para sí. Mas nunca olvidemos quienes fueron los pioneros, aquellos habitantes de la fantasmagoría y la ficción, quienes apuntaban hacia esa verdad que por entonces nadie admitía. Porque al fin y al cabo ¿Quién se tomaría en serio unos cuentos de fantasmas?

\section{Referencias bibliográficas}

AYALA, R. (2012). Mitología China. Barcelona: Olimpo.

CASAS, Q. (2014). "Masters of Horror: Una antología de terror moderno". Dirigido por...n. ${ }^{\circ} 449$. pp. 68-69.

CORNU, P. (2012). Diccionario del Budismo. Madrid: Akal.

HEARN, L. (2011). Fantasmas de la China. Madrid: La compañía.

HIDALGO, T. (2020). "Netflix como productor audiovisual". Obra Digital: Revista de Comunicación. n. 19. pp. 117-132.

MALPARTIDA, R. (2015). Espectros de Cine en Japón. Gijón: Satori.

MíGUEZ, A. (2021). Kaidan. Tradición del Terror en Japón. Córdoba: Berenice.

OLIVARES, J. (2005). The Ring: Una mirada al abismo. Madrid: Jaguar. 
ANTONIO MÍGUEZ SANTA CRUZ

FANTASMAS DEL LEJANO ORIENTE. MITOLOGÍA Y PLASMACIONES EN LA SERIE FOLKLORE DE HBO

THEROUX, P. (1977). The Consul's File. Londres: Hamilton. 